\title{
Identification of moisture transport mechanism in gypsum during convective drying
}

Adamski, R.; Adamska, A.; Pakowski, Z.

Faculty of Process and Environmental Engineering Lodz Technical University, Lodz, Poland

*E-mail of the corresponding author: robert.adamski@p.lodz.pl

\begin{abstract}
Gypsum is a popular building material. Drying and rewetting of gypsum is a process of practical importance. This work presents the experimental results of kinetic of drying, heating and internal pressure development in rewetted gypsum cylinders. Analysis of the observed changes is presented. Additionally sorption isotherms, permeability and dependence of Young's modulus on moisture content were measured. These data will be used in the model of the process under development.
\end{abstract}

Keywords: internal pressure, permeability, Young's modulus 


\section{Introduction}

Gypsum is commonly used as a building material in the form of gypsum blocks, plasterboards, fillers and renders. It is also used by other industries e.g. ceramic industry for making molds. In buildings moisture in gypsum materials is present both during setting and normal use due to its hygroscopicity. It influences energy consumption, air quality in houses and durability of the material. It is therefore important to know more about the mechanism of heat and moisture exchange with surroundings and their transfer in the gypsum materials. Literature of the subject is abundant in models which serve for prediction of spatial and temporal variations of temperature and moisture content in building materials. The models usually require performing experimental determination of model parameters like specific heat, heat conductivity, moisture diffusivity [1,2] and permeability [3,4]. The knowledge of microstructural changes and interactions of water and the material of crystalline structure like gypsum, especially in heat and mass transfer processes is one of key issues influencing mechanical properties of the gypsum products. Gypsum materials change their mechanical properties depending on their wetness and the reason are week bonds of crystalline adhesions. Repeating cycles of humidificationdehumidification may lead to shrinkage, deformations and cracks as described in numerous publications [5]. Several works concentrate on heat and mass transfer during drying of building materials like plasterboard, and wood [6], brick and render including determination of moisture content profiles [7], analysis of external parameters as pressure [8], wind speed [9] and analysis of the determination of the influence of drying kinetics [10] on distribution of stresses in the material.

The aim of this work is to experimentally analyses the drying process of gypsum by measuring its kinetics of mass, temperature and internal pressure in drying and measure necessary parameters i.e. sorption/desorption isotherms, Darcy permeability and Young's modulus of wet gypsum. These observations will be used in the model of drying including stress development in the solid (under construction).

\section{Materials and Methods}

Commercial gypsum powder of building grade produced by Piotrowice company under a brand name Alpol. It is destined for using as building material and filler as well as for casting of prefabricates. The powder was mixed with recommended water/gypsum ratio equal to 0.65 . Cast gypsum is a material that doesn't shrink during drying.

\subsection{Sorptional equilibrium}

Desorption isotherms at low temperature were measured by a standard method of saturated salt solutions at $20^{\circ} \mathrm{C}$ and $50^{\circ} \mathrm{C}$ and atmospheric pressure. Additionally experiments were 
made in superheated steam in the range of temperatures of $120^{\circ} \mathrm{C}$ to $200^{\circ} \mathrm{C}$ in a separate set-up also at atmospheric pressure

\subsection{Drying kinetics}

Drying experiments were performed in a drying tunnel described elsewhere [18]. Cylindrical samples $28 \mathrm{~mm}$ in diameter and $54 \mathrm{~mm}$ high were used. Drying was performed at $50^{\circ} \mathrm{C}$ and air velocity of $1 \mathrm{~m} / \mathrm{s}$. Air humidity was not controlled.

\subsection{Permeability}

Permeability was measured by hydraulic method described elsewhere [12] using compressed air permeation. Gypsum disks $13 \mathrm{~mm}$ in diameter and $2 \mathrm{~mm}$ thick were used. Experiments were made on dry gypsum which was then soaked . Measurements were made in duplicate.

\subsection{Mechanical properties}

For modeling of drying stresses the dependence of Young's modulus on moisture content is required. The dependence was measured using seasoned gypsum samples of given moisture content and standard Instron testing machine. The experiments were made in duplicate.

\section{Results}

\subsection{Sorptional equilibrium}

The results are shown in Fig. 1 in the form of 3D dependence of moisture content $\mathrm{X}$ on water activity $\mathrm{a}_{\mathrm{w}}$ and temperature T. Two isotherms for $20^{\circ} \mathrm{C}$ and $50^{\circ} \mathrm{C}$ and an isobar in the range $120^{\circ} \mathrm{C}-200^{\circ} \mathrm{C}$ are shown. It is visible that equilibrium moisture content rapidly increases with water activity and slowly decreases with temperature. This indicates that gypsum is only slightly hygroscopic.

The data points were fitted with Chen and Clayton equation (1) with coefficients available in Table 1 . The fit is of satisfactory quality.

$$
a_{w}=\exp \left(a_{1} T^{a_{2}} \exp \left(a_{3} T^{a_{4}} X\right)\right)
$$

Table 1. Coefficients of equation (1)

\begin{tabular}{|c|c|c|c|c|c|}
\hline \multirow{5}{*}{ 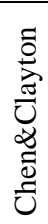 } & \multirow{2}{*}{$\frac{\text { Coeff. }}{\mathrm{a}_{1}}$} & \multirow{2}{*}{$\begin{array}{c}\text { value } \\
-14,107\end{array}$} & \multicolumn{2}{|c|}{ Confidence interval } & $\mathbf{R}^{2}$ \\
\hline & & & $-26,516$ & -1,698 & \multirow{4}{*}{0.963} \\
\hline & $\mathrm{a}_{2}$ & $-0,344$ & $-0,575$ & $-0,112$ & \\
\hline & $\mathrm{a}_{3}$ & $-1.283 e 6$ & $-2.221 \mathrm{e} 6$ & $-3.461 \mathrm{e} 5$ & \\
\hline & $\mathrm{a}_{4}$ & $-2,515$ & $-2,732$ & $-2,298$ & \\
\hline
\end{tabular}




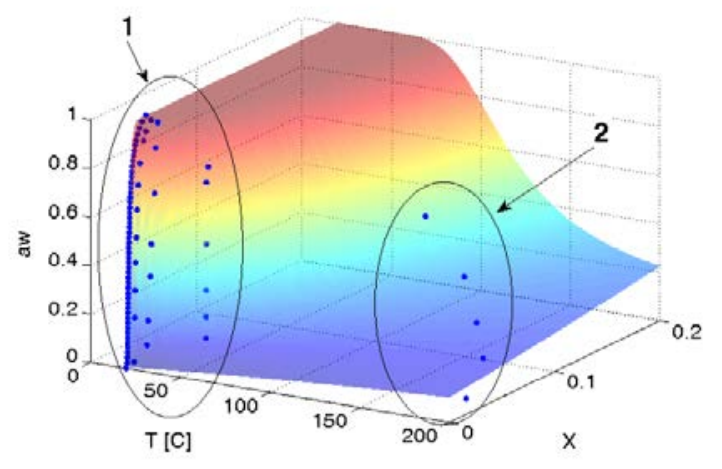

Fig. 1 Dependence of equilibrium moisture content on water activity and temperature 1-isotherms $20^{\circ} \mathrm{C}$ and $50^{\circ} \mathrm{C}$, 2-isobar.

\subsection{Drying kinetics}

An exemplary test run results are shown in Fig. 2. Fig. 2a shows how air parameters: atmospheric pressure, temperature and water activity vary during the process.
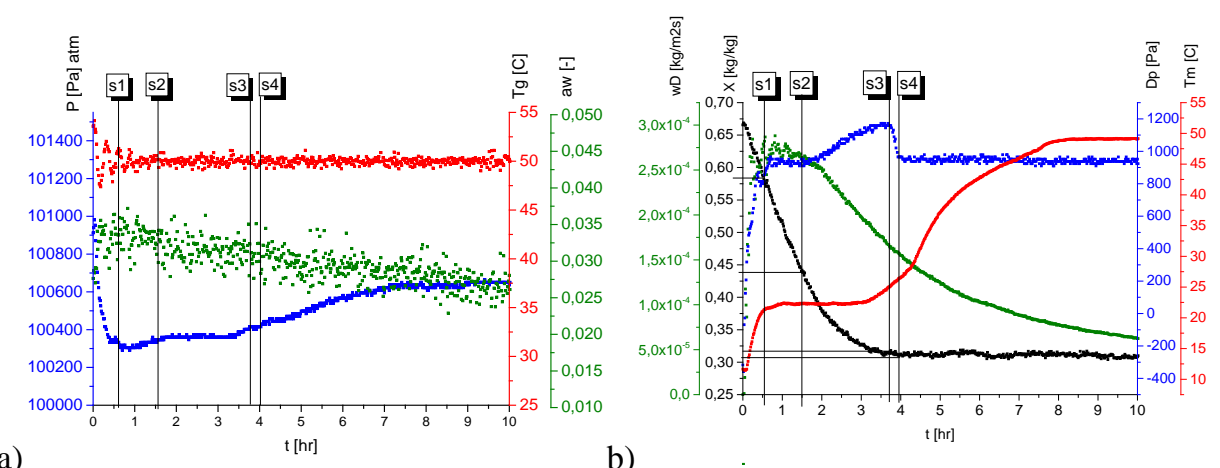

Fig.2. a) Air parameters, b) Drying kinetics at $50^{\circ} \mathrm{C}$

A sample of initial $\mathrm{MC}=0.67 \mathrm{kgkg}^{-1} \mathrm{dm}$ and temperature $12^{\circ} \mathrm{C}$ is dried with air of temperature $50^{\circ} \mathrm{C}$ and $\mathrm{RH}=3.5 \%$. In the time range from 0 to $\mathrm{S} 1$ the solid heats up to the wet-bulb temperature. During that time MC decreases to $0.57 \mathrm{kgkg}^{-1} \mathrm{dm}+$ and internal pressure rapidly decreases to $-400 \mathrm{~Pa}$ and then rises to $+900 \mathrm{~Pa}$. The initial pressure drop may be a result of fast evaporation at still initial axial temperature. The mass flux "drags" water from the inside creating underpressure. When the axial temperature increases thermal expansion of liquid causes pressure to rise. At the end of this time drying rate reaches $2.75 \mathrm{e}-4 \mathrm{kgm}^{-2} \mathrm{~s}^{-1}$.

In this phase of the process the solid is saturated and the dominating mechanism is Darcy flow. It is worth noticing that while the axial pressure is negative, the inner part of the 
sample is compressed and when positive it is stretched. If the resulting stress should exceed material strength the solid would crack.

The time range from S1 to S2 corresponds to CRP where MC decreases from initial value $0.57 \mathrm{kgkg}^{-1} \mathrm{dm}$ down to $0.47 \mathrm{kgkg}^{-1} \mathrm{dm}$, The dominating mechanism is Darcy flow in liquid phase. From S2 to S3 we have the FRP - drying rate decreases, the temperature increases to $25^{\circ} \mathrm{C}$ and internal pressure increases to $+1200 \mathrm{~Pa}$, reaching maximum. In this range mass transport takes place in liquid phase, vapor phase and gas phase of water vapor and air, and a penetration of the evaporation front is observed. As proposed in [11] the transport fluxes are: water in liquid phase where the driving force is pressure gradient in liquid phase, flux in vapor-gas phase driven by pressure gradient, diffusional flux in gas phase driven by vapor concentration gradient and finally flux of bound water with MC as the driving force. The last two fluxes govern the range from S3 to S4 where MC decreases to the equilibrium value, pressure decreases to $+900 \mathrm{~Pa}$ and temperature increases. In the remaining time all parameters remain constant except temperature which increase further reaching the external air temperature.

\subsection{Permeability}

Permeability was measured according to the Polish National Standard PN-EN 993-4. The governing Darcy equation has the form:

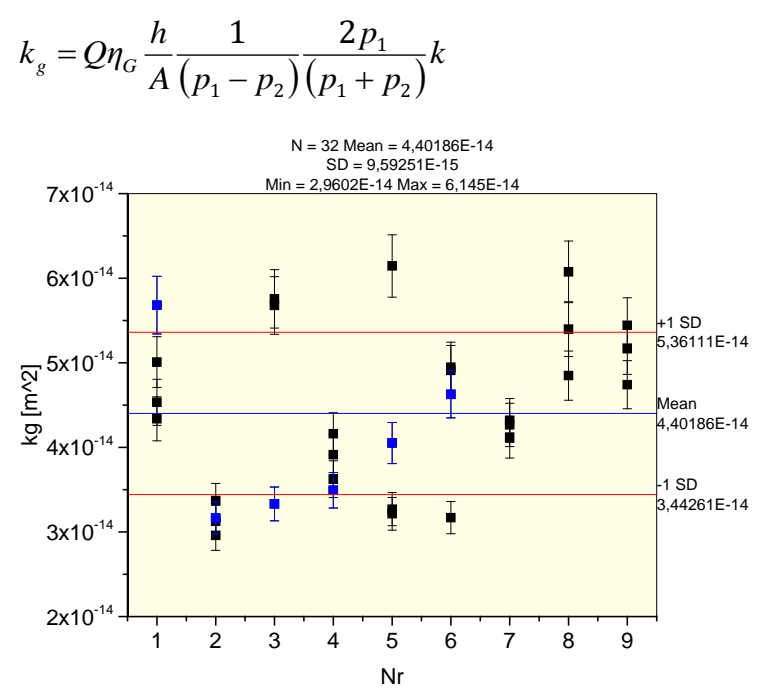

Fig.3. Permeability of samples (black - dry, blue - wet)

In this work actual pressure varies in time while in PN-EN 993-4 is steady. Another difference is that the quoted standard requires samples of cylindrical shape $50 \times 50 \mathrm{~mm}$ 
while in our experiments samples were much smaller. Experimental error was estimated as less than $6 \%$. The results are shown in Fig. 3 both for dry and wet samples of MC=0.65 $\mathrm{kg} / \mathrm{kg}$. The straight blue line is the mean value of $4.40 \cdot 10^{-14} \mathrm{~m}^{2}$ and the red lines are at 1 standard deviation off this value. The entire range of results for wet sample was $3 \cdot 10^{-14} \mathrm{~m}^{2}$ to $6 \cdot 10^{-14} \mathrm{~m}^{2}$. Similar values were obtained in [13] by the method of PN-EN 993-4 [3,14]. The values for wet samples were in the range $3 \cdot 10^{-14} \mathrm{~m}^{2}$ to $5 \cdot 10^{-14} \mathrm{~m}^{2}$.

\subsection{Mechanical properties}

Strength of plaster is a results of bonds between the forms of gypsum (anhydrite, semihydrate and dihydrate), sulfur compounds, water and residuals [15]. Typically compression and bending strength are measured, rarely the Young's modulus [16]. Mechanical characteristics of plaster depend mainly on porosity, placement and structure of gypsum crystals formed during hydration of calcined gypsum [17]. On the other hand they also depend on the actual condition of plaster resulting from ambient conditions like temperature and humidity. Although gypsum sets in ca 25 min after mixing with water it reaches full mechanical strength after 28 days according to ASTM C215, 1991. Only then the mechanical tests can be performed. The results of this work are shown in Fig. 4.

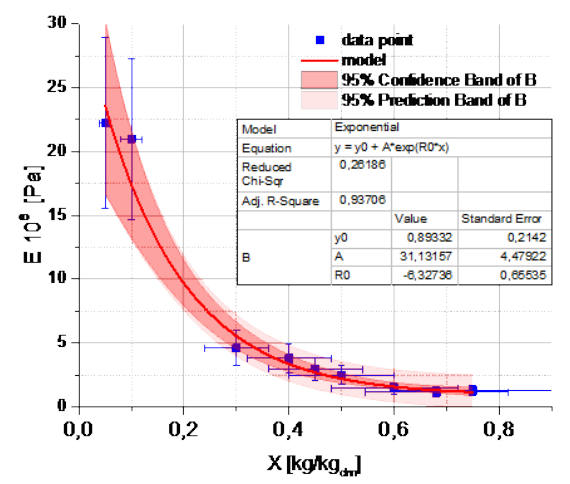

Fig.4. Young's modulus dependence on moisture content of rewetted gypsum

The approximating equation has the form:

$$
E=[0.89332+31.13157(\exp (-6.32736 X))] \cdot 10^{8}
$$

\section{Conclusions}

Results of this work indicate that hardened gypsum is slightly hygroscopic as sorption isotherms indicate and bound water range at room temperature is below MC of ca. 0.03 $\mathrm{kg} / \mathrm{kg}$. It also shows negligible shrinkage in drying. Yet MC significantly influences the Young's modulus, which exponentially decreases with increasing MC. 
During convective drying gypsum exhibits the initial drying period (IDP), constant-rate period (CRP) and falling drying period (FRP). However the internal pressure is only partly related to these periods. In the IDP pressure first rapidly decreases to ca. $-400 \mathrm{~Pa}$ and then increases to $+900 \mathrm{~Pa}$. Ic CRP the pressure first stabilizes and at the final stage of CRP begins to increase. It continues to increase in FRP reaching the maximum of $+1200 \mathrm{~Pa}$ and at the end of the FRP it falls again to $+900 \mathrm{~Pa}$. These variations cause changes in internal stresses. The observed changes of pressure shed some light on moisture transport in the solid which only can be explained with a suitable model. The work on the model is in progress.

\section{Nomenclature}

$\begin{array}{lll}\text { A } & \text { area } & \mathrm{m}^{2} \\ \mathrm{E} & \text { Young's modulus } & \mathrm{Pa} \\ \mathrm{Q} & \text { flow rate } & \mathrm{m}^{3} \mathrm{~s}^{-1} \\ \mathrm{~T} & \text { temperature } & { }^{\circ} \mathrm{C} \\ \mathrm{X} & \text { moisture content } & \mathrm{kgkg}^{-1} \\ \mathrm{~h} & \text { flow path length } & \mathrm{m} \\ \mathrm{k} & \text { correction coefficient } & \\ \mathrm{P} & \text { pressure } & \mathrm{Pa}\end{array}$

Greek letters
$\eta_{G}$
Viscosity of air
Pa s

Subscripts

$\begin{array}{ll}1 & \text { in } \\ 2 & \text { out }\end{array}$

\section{References}

[1] Adan, O. C. G., Determination of moisture diffusivities in gypsum renders. HERONENGLISH EDITION-,1995 40, 201-216.

[2] Bennamoun, L., Kahlerras, L., Michel, F., Courard, L., Salmon, T., Fraikin, L., Léonard, A., Determination of moisture diffusivity during drying of mortar cement: experimental and modeling study. International Journal of Energy Engineering, 2013, 3(1), 1-6.

[3] Milsch H., Priegnitz M., Blöcher G., Permeability of gypsum samples dehydrated in air, Geophysical Research Letters, 2011, 38, s.2-6.

[4] Lee, C. Y., Water desorption characteristic of red gypsum, 2015 
[5] Beyea S.D., Balcom B.J., Bremner T.W., Prado P.J., Cross A.R., Armstrong R.L., Grattan-Bellew P.E., The influence of shrinkage-cracking on the drying behaviour of White Portland cement using single-point imagining (SPI), Solie State Nuclear Magnetic Resonance, 1998, vol. 13, pp. 93-100

[6] Pasanen A.L., Kasanen J.P., Rautiala S., Ikäheimo M., Rantamäki J., Kääriäinen H., Kalliokoski P., Fungal growth and survival in building materials under fluctuating moisture and temperature conditions, International Biodeterioration and biodegradation, 2000, vol. 46, pp. 117-127

[7] Karoglou M., Moropoulou A., Krokida M.K., Maroulis Z.B., A powerful simulation for moisture transfer in buildings, Building and Environment, 2007, vol. 42, pp. 902912

[8] Yoo J.H., Lee H.S., Ismail M.A., An analytical study on the water penetration and diffusion into concrete under water pressure”, Construction and Building Materials, 2011, vol. 25, pp. 99-108

[9] Jacobsen S., Aarseth L.I., Effect of wind on drying from wet porous building materials surfaces - A simple model in steady state, Materials and Structures, 1999, vol. 32, pp. 38-44

[10] Moropoulou A., Karoglou M., Giakoumaki A., Krokida M.K., Maroulis Z.B., Saravacos G.D., Drying kinetics of some building materials, Brazilian Journal of Chemical Engineering, 2005, vol. 22, pp. 203-208

[11] Whitaker S., Simultaneous Heat, Mass, and Momentum Transfer in Porous Media: A Theory of Drying, Advances in heat transfer, 1977, vol. 13

[12] Pakowski Z., Adamski R., Kokocińska M., Cross-fiber dry wood Darcy permeability of energetic willow Salix viminalis v.Orm, Drying Technology, 27: 1379-1383, 2009

[13] Pawlak M., The influence of composition of gypsum plaster on its technological properties, Archives of Foundry Engineering, 2010, vol.10, 4, 55-60

[14] Wang Q., Liu H., The Experimental Research on the Water Vapour Permeability of Construction Gypsum Plaster Materials, Materials for Renewable Energy \& Environment, 2011, s.850-854.

[15] Singh, M., Role of Phosphorgypsum Impurities on Strength and Microstructure of Selenite Plaster. Construction and Building Materials, 2005, Vol. 19pp. 480-486.

[16] Verbeek, C.J.R., du Plessis, B.J.G.W., Density and Flexural Strength of Phosphorgypsum-polymer Composites, Construction and Building Materials, 2005, 19, pp. 265-274.

[17] Singh, M., Garg, M., Relationship between Mechanical Properties and Porosity of Waterresistant Gypsum Binder. Cement and Concrete Research, 2, 1996, pp. 449-456

[18] Pakowski Z, Adamski R., Formation of underpressure in an apple cylinder during convective drying, Drying Technology,, 30: 1238-1246, 2012 